\title{
HYDATID DISEASE
}

\author{
By James A. JENKINS \\ Dunedin, N.Z.
}

Hydatid* disease in man may present a simple surgical problem, or it may be as impossible of eradication as a widely metastasized malignant tumour. The life cycle of the parasite is fully described in textbooks on surgery and in this paper certain less known aspects only are dealt with. Methods of prevention are also excluded, though it should be widely known that there is no disease that so readily lends itself to complete eradication. Infestation occurs in early childhood. There is little evidence that infection arises later in life or, if it does, one must assume that it is usually overcome by the host.

The hexacanth embryo on emerging from the hydatid ovum is an actively motile structure of about 25 microns. It probably reaches the liver via the portal circulation within a few hours of the eggs being swallowed. If several ova are swallowed multiple primary cysts may be formed (6o per cent. of cases). The embryo may pass the filter of the portal circulation and lodge in the lungs, giving rise to a 'primary' lung cyst. If it succeeds in passing the lungs a primary peripheral cyst may develop in any structure of the body. Peripheral cysts occur in muscles in about 4 per cent., in borie in 2 per cent. and in the kidneys in 2 per cent. of cases. It should be emphasized however that between 60 and 70 per cent. of primary cysts occur in the liver, the lungs being next with about 23 per cent. If a primary cyst disseminates its contents to other parts of the body the results are known as 'secondary' cysts. This dissemination may be by way of the blood stream or across the pleural or peritoneal cavities. The liver should always be carefully examined for a primary .cyst if cysts are found elsewhere.

When the hexacanth embryo reaches its destination it develops into a small vesicle and this, acting as a foreign body to the host, causes a cellular reaction in the tissues which later becomes a fibrous membrane-the pericyst. Within the pericyst the vesicle gradually develops two layers which form the wall of the hydatid cyst proper. The outer layer, the ectocyst, laminated membrane or chitinous layer, forms the bulk of the cyst wall whilst the inner layer, the endocyst, parenchymatous or germinal layer, is a structure of micro-

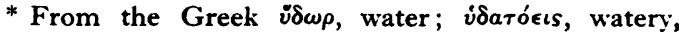
like water, referring to the contents of the cysts.
}

scopic thinness which produces brood capsules with their scolices and perhaps daughter cysts. Not until the cyst reaches a certain size are brood capsules formed. These tiny structures develop scolices, some of which become free in the clear fluid content of the cyst. The resemblance of the brood capsules and scolices to fine sand has led to the use of the term ' hydatid sand.'

Scolices and brood capsules are capable of developing into fully formed hydatid cysts if they gain entrance to serous cavities, wound surfaces or the blood stream. It is unfortunate that the term ' sterile cyst' has crept into the literature as all cysts are potentially dangerous in regard to powers of dissemination. A ' sterile cyst' is a univesicular cyst as opposed to a cyst containing daughter cysts, and it is 'sterile' only in the sense that it has not yet produced daughter cysts, but its capacity for spreading the disease widely is only too often demonstrated in countries where hydatids abound. If the cyst is threatened by trauma, lack of nourishment, the irritation of infection in the pericyst, leakage of some of its contents into an adjacent duct' or cavity, or leakage of some foreign substance such as bile into the cyst, then its continued survival is safeguarded by the formation of daughter cysts. These daughter cysts, like the scolices and brood capsules, are capable of growing into fully formed hydatid cysts. The daughter cysts vary greatly in size and number, but are usually from $\frac{1}{2}$ to 2 in. in diameter. They are replicas of the mother cyst.

The pericyst plays a very important part in the life of the hydatid. Through it the cyst receives nourishment but, as time goes by, the pericyst reaction which represents the host's tissue response to a foreign body becomes greater and the nourishment of the cyst suffers. Degenerative changes and calcification are commonly found in the wall of the pericyst. Tissues such as brain and spinal cord fail to form pericysts. It is often badly formed in the lung. It is important to remember that the pericyst or adventitious layer is part of the host and attempts at its surgical removal lead to disaster unless it is in a free and accessible position, where it can be removed together with the organ containing the cyst (such as the kidney or lobe of a lung). Where the pericyst is lacking, the hydatid thrives on the nourishment it obtains from the surrounding tissue fluid. 
The cyst may ' die,' becoming a pultaceous mass surrounded by a thick and often calcified pericyst. A calcified, puckered cicatrix may be all that remains of a mother cyst. It is very difficult to be certain in the 'dead cyst' that there are no viable elements.

In most cases the hydatid continues to grow until space-occupying symptoms (pressure effects, deformity, pain), infection, leakage (into a duct such as a bronchus or bile duct, or to a serous surface) or toxic manifestations from the absorption of antigens bring the patient up for investigation. It is a not infrequent occurrence to find a cyst when operating for other conditions, or at post mortem, there being no past symptoms referable to the hydatid.

Suppuration arises most commonly in cysts closely associated with ducts such as the intrahepatic bile ducts, the bronchi, or the intestinal or urinary tract. A cyst in a conspicuous site may bring the patient at an early stage. For example a girl of 22 presented herself with a prominent cystic swelling $I$ in. in diameter in the lower part of the posterior triangle of the neck. It was found on removal to be a hydatid cyst. There was no evidence of cysts elsewhere. Cysts in the right lobe of the liver may reach enormous proportions before the patient is aware that anything is wrong. Leakage from a cyst causes acute anaphylactic symptoms whilst its sudden rupture into a serous cavity or duct, or the disaster of intravascular rupture may produce an acute emergency. Cysts in confined areas such as the spinal canal, cranium or pelvis may early produce marked symptoms by pressure on neighbouring structures.

\section{Rate of Growth of Primary Hydatid Cysts}

The rate of growth varies enormously and the ' soil' appears to be the determining factor. The vascular supply of the host's tissues is of paramount importance. The fibrous pericyst eventually suffers thickening and degeneration which limits growth and excludes from the cyst the nourishment required. Limitation of expansion by the density and fixity of surrounding structures may also check its rate of growth. The most rapid growth is seen in the case of liver cysts in young children.

Case A.-Illustrating rapid rate of growth in a liver cyst.

A child aged three years was admitted to the Dunedin Hospital in August, I934, on account of distension of the abdomen. The mother stated that she had noticed this swelling only one month previously and that it was increasing. The child had not shown any discomfort. On examination the abdomen was grossly distended by a tumour which filled the epigastrium and right hypo-a chondrium. It appeared to be continuous with the liver and extended to well below the umbilicus. It was smooth, firm and elastic. Both hydatid $\stackrel{\varrho}{c}$ complement fixation and Casoni reactions were negative. Eosinophilia, 7 per cent.

At operation a tense cyst about 6 inches in diameter was found within the right lobe of the liver. It proved possible to suture the parietal $\frac{\text { क }}{6}$ peritoneum to a fibrosed area in the liver where the $\frac{\widehat{\Phi}}{\varrho}$ cyst approached the surface. The cyst was theng aspirated and the membranes were removed ${ }_{\overrightarrow{0}}^{\text {s }}$ apparently intact. There were no daughter cysts. Formalin solution was not used. The cavity was $\vec{\omega}$ filled with saline and the opening in the pericysto closed without drainage. Convalescence waso satisfactory there being no infection in the cavity and no leakage of bile. The hydatid complementiv fixation test became strongly positive three weeksin after operation. The Casoni test remained $\stackrel{\infty}{-}$ negative.

At the age of four years the child was admitted for tonsillectomy and was reported as being wello apart from the throat condition. At the age of five years she was admitted with otitis media and the record states then that the liver was enlarged two-⿳亠丷厂 thirds down to the umbilical plane.

At the age of six years she was readmitted undêr $\overrightarrow{0}$ my care. Her mother had noted an abdomitai le swelling and also the fact that the ribs on the rigetit? side appeared to be pushed out. The hydatid complement fixation and Casoni tests were negative. The abdominal condition was very like that seen three years previously. The right lower ribs showed a distinct bulge (Fig. I).

At operation (1.4.37) there were no adhesions 3 between the liver and the parietal peritoneum, and? the abdominal wall was closed over an iodineo gauze pack placed over the surface of the liver $-\overline{\bar{O}}$ On 16.4.37, part of the pack was removed and cyst was aspirated. After it had been emptied theo remainder of the gauze was removed. The hydatid. membranes were lifted out and the pericyst cavityo thoroughly irrigated with saline. There were no daughter cysts present. A tube was inserted to음 drain the cavity. Again no formalin was used. $\rightarrow$ Apart from some pulmonary complication convalescence was 'uneventful and the sinus healedr within three months. She has been the subject of a careful follow up and to date there is no sign of recurrence.

Comment. This child, when aged three years had a cyst 5 to 6 in. in diameter. The rate ofo growth appears to have been abnormally rapidळ but shows what may occur. The omission to use $\mathrm{e}^{+}$ formalin was a mistake. It is probably the most effective lethal agent we have for scolices-2 per cent. formalin killing these within five minutes. 
My reason for not using it at this period was an unhappy experience of its great toxicity both locally on the tissues and generally through absorption. It has to be used with great care. It should never be injected into lung cysts, or into liver cysts if there is the possibility of communication with a large bile duct. It can be safely swabbed over the interior of the pericyst on occasions when injection into the cyst is not considered safe. It is probably of little use when a mother cyst is packed with daughter cysts, as it has no opportunity of making contact with the contained scolices.

The lung appears to be the next most favourable site for rapid growth, but symptoms or complications caused by the cyst are liable to bring the patient to treatment relatively earlier than in the case of liver cysts. Cysts of 3-4 in. in diameter are not uncommon in children under the age of eight years, as in the following example.

Case B.-Illustrating rate of growth in the lung.

A child, eight years of age, was admitted to hospital on 24.11 .42 with a history of pain in the right side of the chest, and of slight cough for I I weeks. A diagnosis of pleurisy had originally been made, but X-rays (Fig. 2) disclosed a large cyst in the right lung. On 30.1 1.42, under local anaesthesia, 3 in. of the eighth and ninth ribs were removed in the posterior axillary line. The pleura was not adherent. Through a small opening sterile talc was smeared on the pleural surface over the cyst, an extrapleural iodine gauze plug was applied and the wound tightly closed. On I0.12.42, under local anaesthesia, the wound was reopened, and the cyst removed. There was no bronchial communication. A tube was placed in the resulting cavity. The patient was discharged on 22.1.43, healed and symptomless.

Comment. Some surgeons prefer general anaesthesia to lessen the risk of anaphylaxis from spill of hydatid fluid. When treated in two stages the simple peripheral cyst with a non-adherent pleura presents usually little difficulty. Opening of the pleural cavity is unnecessary for a cyst presenting on the lung surface, as a firm iodine gauze pack left in the extrapleural space produces satisfactory adhesions which enable the pleura to be incised safely at a second stage.

Secondary cysts in the peritoneal cavity do not appear to grow as rapidly as primary cysts in other situations. Multiple abdominal cysts arising from leakage from a liver cyst probably commence their growth in late childhood or early adult life, when rupture is most common. The resistance of the host's tissues, ' the soil,' is fortunately greater, and it is also possible that the second generation of cysts is less active than the first.

The rate of growth in bone is difficult to assess as the cyst undergoes a marked change in its mode of growth in this structure. Following the line of least resistance along the interstices of the cancellous tissue and the medullary canal, extracystic budding occurs and a rib or a long bone may become involved from end to end by this exogenous growth. The medullary cavity and cancellous tissue become riddled by thousands of cysts, varying in size from a pin's head to a cyst a third of an inch in diameter.

In general the rate of growth of cysts in all organs gets progressively slower as the age of the cyst increases. The important part the pericyst plays in food supply to the cyst has already been mentioned. Many cases, undoubtedly childhood infections, come to operation for the first time in middle age when the cyst has found its environment less favourable owing to the onset of some complication.

\section{Peculiarities of Growth in Various Organs}

The organ or structure in which a hydatid cyst is lodged exerts a marked effect on the development of the cyst, its contents and the liability to complications. A brief survey is here given of the outstanding characteristics of cysts in various situations.

\section{HYDATIDS OF THE LIVER}

Between 60 and 70 per cent. of all cysts occur in the liver. This is to be expected when the method of spread and the life history. of the hydatid are considered. The right lobe being larger than the left is correspondingly more commonly involved. The cyst usually continues to grow until one or more of the following complications bring the patient for treatment.

I. Pressure. This may cause (a) deformity, either a marked bulging of the abdominal wall or a deformity of the overlying chest wall (Fig. I). (b) Pain which may be localized to this area or referred to the shoulder owing to involvement of the diaphragm. (c) Gastro-intestinal symptoms (Fig. 5). (d) Respiratory and cardiac embarrassment and signs of obstruction to the portal vein or inferior vena cava.

2. Infection. Infection causes a subacute or chronic liver abscess. Due to erosion of bile ducts, infection is a common occurrence in old standing cysts in middle-aged and elderly people. Pain and cachexia may be a marked feature. Depending on the site of the hydatid cyst the abscess may be entirely intrahepatic or may form a subphrenic collection. Secondary septic involvement of the pleural cavity is not uncommon.

Case C.-Illustrating pressure symptoms and grave infection. 
A woman, aged 68 , was seen on 3.3 .47 complaining of pain in the right side of the abdomen of some months' duration, and of marked loss of weight and strength. She looked desperately ill and was extremely breathless, with a rapid weak pulse. The apex beat was in the fourth intercostal space in the left mid-axillary line, the heart being pushed over and rotated. A large mass filled the right abdomen down to the level of the anterior superior spine of the ilium. The legs were oedematous and there was evidence of marked venous back pressure. Both Casoni and hydatid complement fixation tests were strongly positive. In view of her inability to lie down and her very precarious physical condition, the cyst was exposed under local anaesthesia by an incision below the right costal margin. Fortunately the liver and cyst were adherent to the abdominal wall at this point. A small incision was made through the cyst wall to relieve tension, and gradually two to three gallons of pus and hydatid debris and daughter cysts were allowed to escape. A week later when * her condition had improved the incision was extended under local anaesthesia and the remains of membrane and daughter cysts were removed. The huge cavity extended up to the third rib, and the dislocated heart could be felt impinging on its medial surface. The cavity gradually shrank and the wound was healed in $3 \frac{1}{2}$ months' time. All evidence of pressure symptoms disappeared, as shown by the return of the heart to normal position, and the loss of venous congestion and oedema. All signs of 'hydatid cachexia' also disappeared.

3. Secondary lung complications. 'The cyst may bulge through the diaphragm which eventually gives way, the lung now forming the upper boundary of the cyst. The opening in the diaphragm may not be large, but there may be an extensive cavity both above and below it. tions.

Case D.-Illustrating secondary lung complica-

A male, aged 54 years, was admitted on I6.1 1.42 complaining of pain in the right side of his chest, cough and temperature of eight weeks' duration. He stated that he had had pleurisy and pneumonia seven years previously. He had felt very ill during the past two weeks. The pleural cavity on the right side had been aspirated by his doctor and purulent fluid withdrawn.

Operation, I9.11.42. A rib was resected and a large cavity filled with pus and hydatid debris and daughter cysts was found occupying the lower part of the right pleural cavity. There was an opening through the diaphragm $1 \frac{1}{2}$ in. in diameter communicating with a hydatid cyst in the dome of the liver. After removal of all hydatid membrane and daughter cysts, 2 per cent. formalin was swabbeकी over the wall of the cavity and a drain was insertedz He was discharged healed on 23.3.43.

When seen on 8.10 .43 there was a small sub $\frac{2}{.}$ cutaneous cyst in the chest wall in front of the operation incision. Hydatid complement fixation tests were negative.

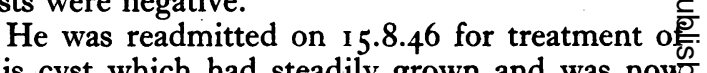
this cyst which had steadily grown and was now causing pain. Examination revealed a tense cystie swelling $3 \frac{1}{2}$ in. by $2 \frac{1}{2}$ in. centred about the mid axillary line in the chest wall. The hydatid com-c plement fixation test was strongly positive. $A$ well marked hydatid thrill was present. Thisw thrill was felt as a sustained coarse vibration per $\frac{\text { s }}{8}$ sisting after firm percussion.

At the second operation there were man daughter cysts present. The adjacent rib and intercostal muscles were infiltrated by hydatids andi all involved tissue was removed en bloc. A further cyst was found below the diaphragm and was emptied. He was discharged healed on r.10.46 0 and when seen in 1947 his hydatid complement fixation and Casoni tests were both still strongl positive.

It can be readily seen that it is but a short steps from this condition to a lung abscess whigh may rupture into a bronchus, and should at same time a biliary communication be present hepato-bronchial fistula is likely to result. La察 quantities of bile may be expectorated by a patièn suffering from this condition.

Case E.-Illustrating secondary lung complica $\stackrel{\circ}{\frac{\Phi}{2}}$ tions.

A male, aged 45 years, was admitted to the medical wards on 21.1.37 with a history of cougle and weakness over a period of seven years. $H$. had coughed up blood-stained sputum and had run irregular temperatures for the past 14 months Past history. In 1916 he was operated on else $\frac{0}{3}$ where for a hydatid of the liver, by a trans thoracic approach, and an empyema had followed There had been further operations of which nơ details are available. Examination showed gross scarring and collapse of the right lower chest The Casoni test was strongly positive both fo immediate and delayed reaction. The hydatidy complement fixation reaction was negative $e_{\mathrm{T}}$ Bronchograms (Fig. 3) disclosed the pressure्巳

effect of the cyst on the lower lobe bronchi.
He was readmitted on 13.7 .37 and transferre $\$$ to the surgical wards. He was very thin, cachectie and in poor condition for surgery. Further X-ra零 investigation confirmed the presence of a cyst at the base of the right lung (Fig. 4). Operation was performed under local anaesthesia and a large cavity containing pus and hydatid debris waक्ष 
found. Free drainage was established. The openings of many bronchi could be seen, and these were cauterized.

On 24.8.37 a phrenic avulsion was carried out. He was then transferred to a convalescent home, the fistulae still being open. He was readmitted a year later under another surgical service with persistent bronchial fistulae. Thiersch grafts of skin from the arm were applied to the walls of the intrathoracic cavity, without benefit. When readmitted on 18.2.39, under my care, his condition was unchanged. Lipiodol injected into the sinus passed directly into the main lower lobe bronchus. All the lower lobe bronchi showed distortion and dilatation.

Operation, 28.2.39. Extensive rib resection was carried out over the right lower chest. The cavity was freely exposed, the whole lining membrane was dissected off with the electric cutting current, and an attempt was made to close the opening into the bronchi by suture. The overlying soft tissues of the chest wall were collapsed down to obliterate the cavity, and were maintained by pressure in this position. $\mathrm{He}$ was discharged on 6.4 .39 , completely healed.

Comment. The cyst in the base of the right lung had presumably originated from the liver cyst operated on 20 years previously. Bronchial epithelium had spread on to the inner wall of the pericyst. Section of the wall removed at operation showed it to be lined by both squamous epithelium and bronchial mucous membrane. It was obvious that the epithelial lining would prevent obliteration of this cavity. A case presenting gross bronchial dilatation and deformity would now probably be better dealt with by lobectomy, but the Schede operation combined with excision of the epithelial lining and closure of bronchi yielded a satisfactory result.

4. Anaphylactic phenomena. Anaphylactic phenomena may be mild, or they may be so intense as to produce coma and death. Diagnostic aspiration of cysts has in the past been a fertile source of both acute anaphylaxis and of dissemination of the disease.

5. Sudden rupture. A sudden rupture into the peritoneal cavity is a rare event but it may cause acute abdominal symptoms. That it may also cause little upset is evidenced by the presence of multiple cysts scattered throughout the abdomen in cases giving no history of rupture.

6. Obstruction of the biliary passages. Obstruction of the biliary passages by daughter cysts occurs too often in endemic areas to be ignored as a cause of acute biliary colic or obstructive jaundice.

7. Beath of cyst. Excessive fibrous reaction in the pericyst, leakage, or low grade infection may cause death of the cyst and this is followed fre- quently by calcification of the pericyst. The content of the cyst becomes pultaceous, progressively inspissated, and later calcified. Such calcified cysts are often discovered by accident in routine $\mathrm{X}$-rays (Fig. 5).

Case $F$.-Illustrating excessive fibrous reaction in pericyst.

In a female, aged 18 years, hydatid cysts in the liver were discovered during the course of an $\mathrm{X}$-ray examination of the spine and she was admitted to hospital on 8.1.43 for further investigation. She appeared to be a healthy young woman and the only abnormality on physical examination was some questionable fullness below the costal margin on each side. Hydatid complement fixation and Casoni tests were strongly positive. Further X-rays showed elevation of the right and left sides of the diaphragm, some calcification in the epigastrium and the evidence of a cyst below the right lobe of the liver. A barium meal showed pressure of the cyst on the fundus of the stomach and the outline of the cyst could be seen below the level of the cupola (Fig. 6).

Operation in January 1943 confirmed these findings. At a first stage the abdomen was opened and the large cyst on the left side was dealt with. After formalization and evacuation it was drained through the left upper abdomen. Theco pericyst was about a quarter of an inch thick, rigid? and non-collapsible. A small cyst was found attached to the liver edge and was excised. An old calcified scar occupied the anterior surface of the right lobe of the liver. Further cysts were palpated, one in the liver below the dome of the diaphragm on the right side, and another below the anterior edge of the liver filling the right flank.

Three weeks after operation drainage became unsatisfactory, the patient becoming toxic and running a high temperature. There were signs of left basal consolidation. The left subphrenic space was entered after rib resection and exclusion of the pleura, and a collection of pus in the space previously occupied by the cyst was drained. Convalescence was uneventful. Three months later the right lobe of the liver was exposed through a Kocher's incision and after careful packing off and formalization, the cyst attached to the edge of the right lobe was emptied and most of the extra hepatic pericyst was excised. After resection of the costal margin and elevation of the pleural reflection a large cyst on the upper surface of the liver was dealt with. Convalescence was uneventful.

Comment. This girl probably had two primary cysts, one represented by the calcified scar in the liver, and the other by the large cyst in the upper part of the right lobe of the liver. I think the other cysts were probably secondary from rupture 
of the old parent cyst in the liver. The very thick and rigid pericyst found at the first operation formed a non-collapsible cavity under the left diaphragm, a cavity which was very slow in closing.

8. 'Colossal peritoneal' cysts. Rupture of a parent liver cyst into the peritoneal cavity may occasionally give rise to colossal cysts that may be mistaken for ascites. Several such cases have been recorded (Barnett, 1927; Robinson and Deve (quoted by Barnett); Hutchinson, 1890; and Syme, 1909). In Barnett's case I I gallons of hydatid material were evacuated. The huge cavity is lined by membrane, partly peritoneum and partly pericyst reaction, but nowhere are viscera seen. The lining membrane of the cavity completely excludes all recognizable intra-abdominal structures. The theory advanced to account for this particular feature is that in the original rupture bile escapes, and the reaction to the chole-peritoneum is a plastic one that obliterates all peritoneal recesses.

\section{Further Considerations of Liver Cysts}

Cysts in the liver tend to display certain characteristics depending on (a) their position in the liver, (b) their relationship to other structures and (c) the intensity and duration of infection.

(a) Position in the liver. Cysts arising in the centre of the right lobe of the liver are surrounded by liver tissue until, as growth proceeds, fibrous pericyst reaches the liver surface. It is this intrahepatic type of cyst which often grows to very large proportions since it is well nourished and protected, and apart from infection or other complications it is unlikely to trouble the patient until it has achieved a very considerable size. It is not uncommon to find a cyst 6-9 in. in diameter presenting both on the anterior and inferior surfaces of the liver. To the touch the presenting liver surface is tense and cystic, and the thinnedout liver tissue often $\frac{1}{4}$ in. or less in thickness is fibrotic and relatively avascular, merging imperceptibly into the pericyst. It is in this type of case that the liver as a whole feels diffusely enlarged, smooth and even when the abdomen is opened. Owing to the replacement of liver tissue by the cyst, hypertrophy of the organ occurs elsewhere and the left lobe of the liver becomes markedly enlarged. Small cysts up to the size of a cricket ball may be easily overlooked if not occupying a situation near to the surface of the liver.

Cysts lying in a peripheral position are correspondingly more easily recognized. If the cyst commences its growth near the liver edge or near. the inferior surface it may reach several inches in diameter with but a small part of its wall actually in liver tissue. It then projects into the peritoneal cavity and in time becomes densely adherent to contiguous structures such as the colon and omentum. Cysts on the under surface of the liver may cause displacement of the right kidney. Cysts arising near the diaphragm may cause marked elevation of this structure but care is necessary to exclude other causes.

Case G.-Illustrating elevation of the diaphragm.

A man, aged 50, was seen in February, 1944, with a large abdominal tumour filling the epigastrium and right hypochondrium. He complained of pain over the right shoulder and in the right side of the chest. The mass in the abdomen was tense and cystic. The hydatid complement fixation test was negative but the Casoni reaction was strongly positive. The radiograph showed a mass in the upper abdomen and marked elevation of the right side of the diaphragm (Fig. 7).

Operation I 1.2.44. Kocher's incision. The costal margin was resected, carefully avoiding the pleura which was stripped up. This provided free exposure of the cyst which was then tapped and the fluid content replaced by 2 per cent. formalin. After a few minutes the formalin waso aspirated, the pericyst opened, and the membranes removed. No daughter cysts were present. (Deto tails of the technique employed to avoid spill are dealt with later.) The pericyst was then sutured to the rectus sheath in the line of the abdominal wall incision. The cavity was filled with saline containing $5 \mathrm{gm}$. of sulphanilamide powder, and the skin incision was closed without drainage. Some days later there was a little fluid discharge and evidence of mild infection, and a tube had to be inserted into the liver cavity. Complete healing took three months.

Comment.-This uncomplicated liver cyst had received no trauma from infection or bile leakage, nourishment had been satisfactory, and consequently no daughter cysts had been produced. It is in this type of cyst that closure of the pericyst, after filling the cavity with saline, may result in early healing. Bile leakage and infection, however, frequently necessitate the later insertion of a drain-a simple procedure in that the pericyst is already sutured to the abdominal incision. Since this operation the hydatid complement fixation has remained suspiciously high, suggesting the possibility of the presence of other cysts.

Multiple cysts are common in the liver, two, three or four primary cysts being not infrequently found. The scar or calcified remains of a primary cyst may be the stimulus that leads to a search of the abdomen for the growing daughter cysts that have resulted from leakage of the parent cyst. 
(b) Relationship to other structures. Cysts in the liver may bear very important relationship to structures such as large bile ducts, main branches of the portal venous system, the vena cava, etc. As the cyst expands it causes local pressure atrophy of the walls of these structures, and the pericyst may even disappear so that the hydatid membrane (ectocyst and endocyst) may actually form, over a small area and probably for a limited time only, the wall of the duct. It is little to be wondered at that when a cyst is opened, due to the great reduction of tension that ensues, the membranes separate from the pericyst and the duct lumen then opens into the resulting cavity within the pericyst. This is the reason why bile so commonly escapes into the cavity after the membranes have been removed. Such leakage may not occur for several days after operation. It also accounts for the disastrous haemorrhage that may occur occasionally (Jenkins I93I). It is the same erosion of ducts that so commonly leads to rupture of the cyst into the biliary tract with subsequent infection within the pericyst, and similarly to escape of cyst contents into the hepatic ducts leading to biliary obstruction by daughter cysts or membrane. A similar leakage of cyst content into the radicals of the vena cava may lead to hydatid embolism of the lungs.

(c) The intensity and duration of infection. The intensity and duration of infection play an important part in the thickness and density of the pericyst, as well as on the reproductive activities and survival of the cyst itself. An uninfected cyst of even 40 to 50 years' growth may have a pericyst of only $\frac{1}{16}$ to $\frac{1}{8}$ in. in thickness because the host's tissues have not received the stimulus necessary to produce much fibrous tissue. If, however, lowgrade infection occurs, the threat of death to the parent cyst causes intense reproductive activity and it becomes packed with daughter cysts and brood capsules. The host's tissues at the same time react and a thick-walled pericyst up to $\frac{1}{4}$ in. of dense fibrous tissue may result.

\section{Alveolar Hydatid Disease of the Liver}

There is an unusual form of hydatid infection known as alveolar hydatid disease, or echinococcosis alveolaris. I operated in February, 1940, on the only case to be reported from New Zealand, and full details of the pathological condition were reported by Meade and Barnett (I94I).

A woman, aged 59, was admitted to the medical wards in 1928 complaining of epigastric pain of two weeks' duration. The liver was then found to be smooth and grossly enlarged. The hydatid complement fixation test was negative. She was treated for hypertension and myocardial failure which were also present. She was fairly well until
1940, when she was admitted under my care com气 plaining of loss of weight and of a tumour in the left upper part of the abdomen. On examinatior the abdomen presented a firm swelling in theepigastrium projecting down to below' the um $\vec{\Rightarrow}$. bilicus. The hydatid complement fixation and Casoni tests were negative. Radiological examination revealed elevation and decreased movement o the left half of the diaphragm with some irregu larity in outline of the right half. The stomach? was displaced by extrinsic pressure.

In view of the long history and uncertainty of diagnosis a laparotomy was performed. A cysit4 in. in diameter bulged from the left lobe of the्w liver. It contained typical gelatinous debris of ats old and degenerated hydatid cyst. Occupying the right lobe of the liver was a hard, finely nodula mass, yellowish grey in colour and looking veryer like secondary carcinoma. A biopsy was takenoo and was sent to the laboratory as a suspected case of alveolar hydatid. The biopsy specimen, presented numerous small cyst-like spaces suro rounded by fibrous tissue, foreign body giant cells? and inflammatory-celled infiltration. The patient became hemiplegic eight days after operation and died in coma on the tenth day. Post mortem? findings are fully recorded in the paper by Meade? and Barnett (1941).

This type of lesion is endemic in Southeri Germany, Switzerland, the Tyrol and tweo Caucasus, and its absence in other parts of the world where hydatid disease is common, led to the belief that there were two different species of echinococcosis. In more recent years sporadic cases have been reported over a wide area and $\overrightarrow{\vec{b}}$ opinion has swung back to the acceptance of bue one species of hydatid, the alveolar form being mutation. Just as the terrain influences the. growth in bone, so under certain as yet unknown? conditions the liver may act in a somewhat similar way. The alveolar hydatid grows by extrusion ans exogenous budding of the germinal layer, then. hydatid ectocyst being poorly developed.

\section{Surgical Treatment of Hydatid Cysts of the Liver}

The majority of cases coming to operation have. laboratory and radiological findings which make the diagnosis of hydatid highly probable. Therf are, however, a number found unexpectedly duro ing the course of abdominal operations for lesions elsewhere, and not uncommonly for supposeck cholecystitis or gall stone disease.

Surgical approach should be planned to give the most direct access if one is certain that only one cyst is present, or if the condition of the patien 5 precludes the immediate treatment of cysts else $\vec{\nabla}$ where. The danger, inherent in a limited exposure $\frac{?}{\mathrm{D}}$ 
of failing to ascertain the presence of other cysts is obvious. Another serious risk is taken, if the exposure is not adequate, of 'hydatid spill,' an accident that may lead to life-long recurrences. I know of no condition requiring greater care to avoid soiling of wound edges and peritoneum than that demanded by a hydatid cyst about to be opened. 'Hydatid asepsis' is essential. A cyst uncomplicated by adhesions, carefully packed off from the wound edge and the peritoneal cavity, on being relieved of some of its fluid content, immediately slides away from the abdominal or chest wall, and what appeared to be a carefully safeguarded area may easily become a danger point for spread of scolices.

It has become an accepted principle to use 2 per cent. formaldehyde solution in an attempt to kill scolices prior to opening the cyst. After the wound and peritoneal surfaces have been packed off, the cyst is tapped by a trocar attached to a tube and funnel, and some hydatid fluid is allowed to run out. This is replaced by formalin solution. Gradually the hydatid fluid is replaced by formalin and at least five minutes are given to allow it to act. Up to this stage there should have been no spill.

Tension sutures are now applied on either side of the proposed incision and when they are in position the formalized fluid within the cyst is aspirated, while simultaneously the tension sutures are pulled on to prevent spill and assure that the wound and peritoneal cavity remain shut off. The cyst may now be incised.

When the cyst tension has been reduced the mother cyst falls away from the pericyst and can be gently removed, often intact, with sponge forceps. If many daughter cysts are present, after an initial gush, a prolonged and careful removal with spoon or large ovum forceps is necessary. The interior of the cavity is then swabbed over with 2 per cent. formalin. In old degenerate cysts part of the parent membrane adheres to the pericyst.

If the mother cyst is tightly packed with daughter cysts the initial formalization fails to reach the scolices and the risk of dissemination is correspondingly greater. There is need for a more efficient and less dangerous antiseptic than formalin solution.

If the surgeon finds the liver adherent to the abdominal wall over the cyst, and he can avail himself of this area, there is no risk of spill, but of course he cannot explore elsewhere. Adhesions are likely to be found in old cysts with superadded sepsis.

There can be no hard and fast rules regarding the surgery of access, and no more than general principles and personal inclinations can be given here.
Definite indications for exploration through the abdominal wall are (I) All cysts that can be reached by this approach ; (2) The presence of obstructive symptoms in the biliary tract; (3) Evidence of hydatids elsewhere in the abdominal cavity.

Definite indication for a posterior transthoracic approach are when intrathoracic complications such as empyema, lung abscess or broncho-biliary fistula complicate a liver cyst that has burst through the diaphragm.

In certain cases of 'dome cysts' presenting posteriorly there is debate as to the advisability of a thoracic approach, either after elevating the pleural reflection and excluding it by suture of the diaphragm to the chest wall, or of doing a twostage operation. The added risk of pleural infestation, and the fact that practically all recognizable cysts can be reached from an anterior transperitoneal approach deter many from adopting the thoracic route.

For the abdominal approach a Kocher's incision, extended as necessary, gives good access to both lobes of the liver and the biliary passages. The high-lying cyst under the right cupola, if large, will usually extend down sufficiently to be accessible through liver tissue below the costal margin. The costal margin may be resected, ando the pleural reflection stripped up, to give as wide an access as required. When the tension of a large cyst is eliminated it may be possible to palpate further cysts.

The treatment of the cavity lined by pericyst left after removal of the cyst raises many problems. If there is bile leakage or evidence of biliary obstruction (in which case the common bile duct should also be explored for daughter cysts) or suppuration, the cavity must be drained. The pericyst is sutured to the opening in the abdominal wall (marsupialization) and convalescence will be slow.

If the daughter cysts are stained yellow from previous bile leakage and the parent membrane is degenerate, it is highly probable that drainage will be required. If the cyst is healthy and uncomplicated it may be filled with saline, and the pericyst 'closed. It is a wise precaution to suture the pericyst to the abdominal wall and leave the abdominal wall in a condition that will permit sinus forceps to pass into the cyst without danger of spread of infection or leakage of bile. Penicillin and sulphanilamide will probably make primary closure safer than in the past, but owing to bile leakage and mild infections the results of primary closure have not been invariably satisfactory in cases generally recognized as being suitable for this form of treatment. Bile leakage into the cavity may be delayed for several days. A compromise may be effected in doubtful cases by 


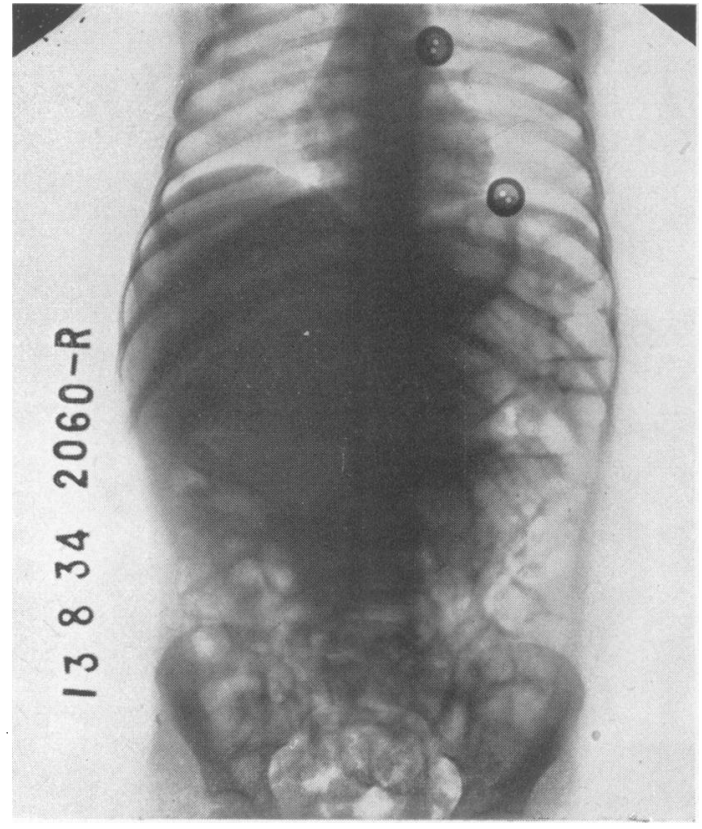

FIG. I.-Case A. Showing recurrent hydatid cyst in the right lobe of the liver occurring in a child of three. The original cyst was operated on at three years ; the recurrence shown, of similar size, at six years of age. Note the bulging of the ribs on the right side.

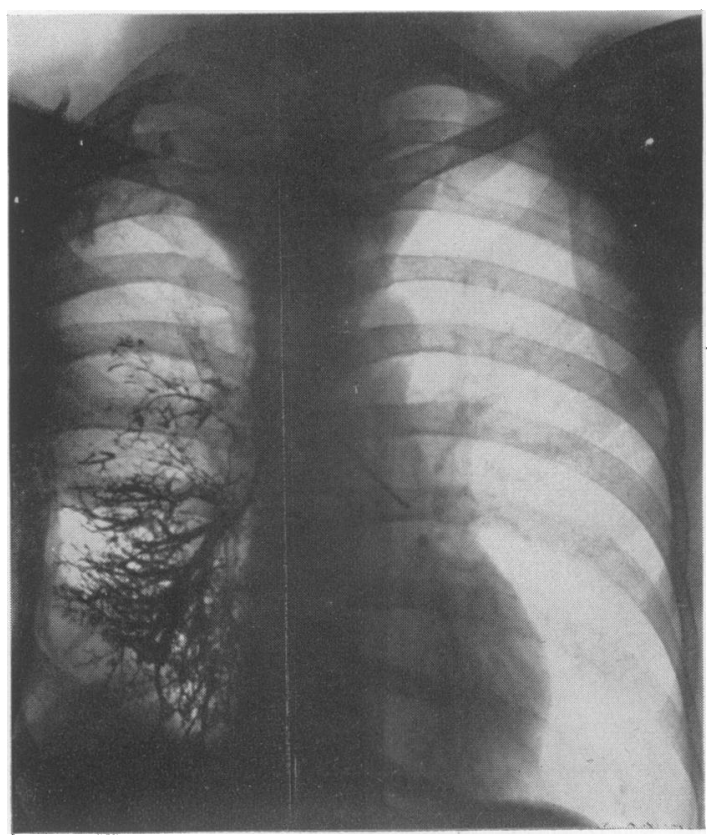

FIG. 3.-Case E. A bronchogram showing pressure effects of the crst on the right lower lobe of the lung.

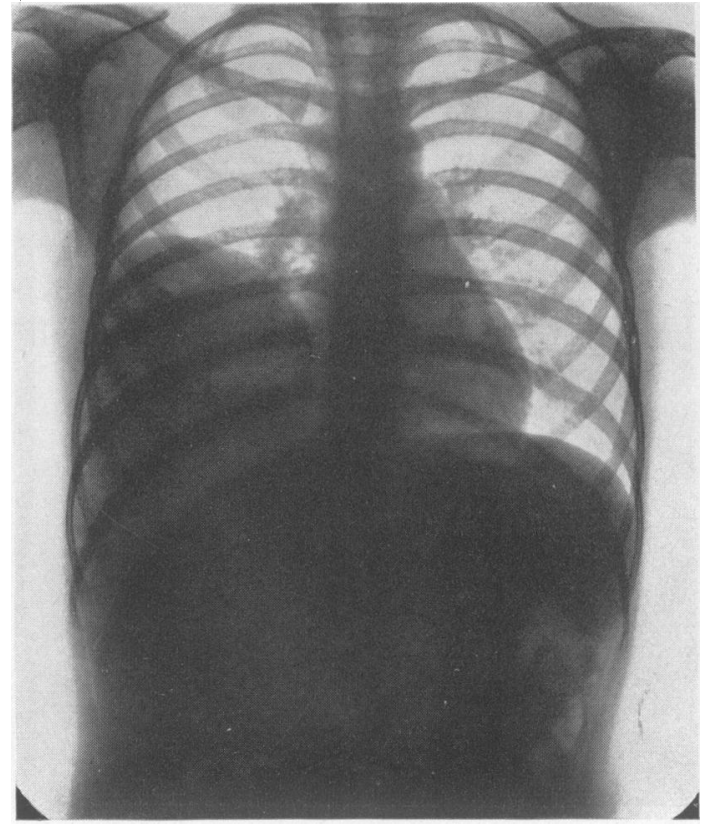

FIG. 2.-Case B. Radiogram of the chest of a child eight years of age illustrating the size to which a lung cyst may grow in the early years of life.

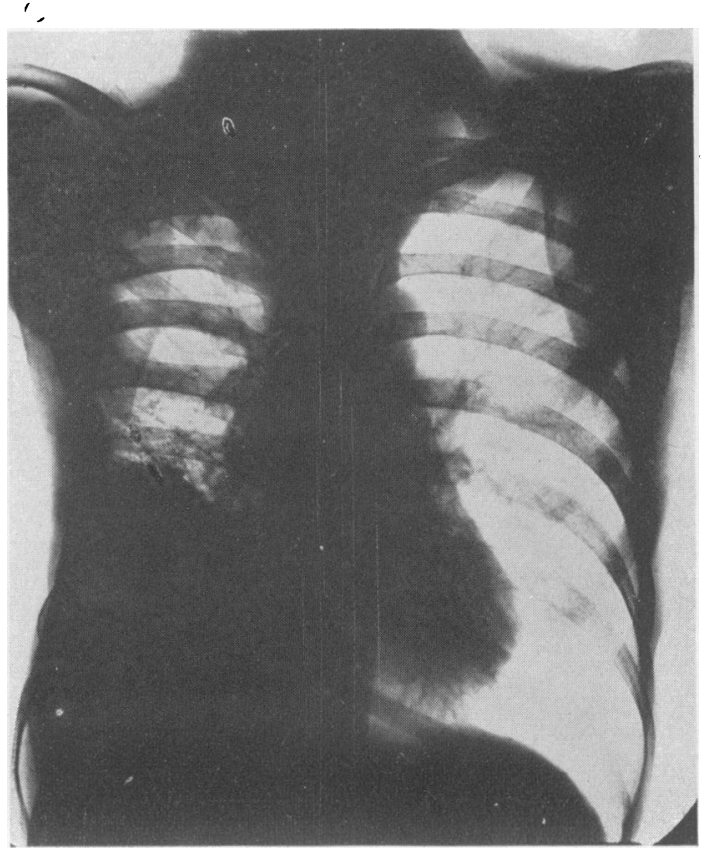

FIg. 4.-Case E. Showing a cyst at the base of the right lung. 


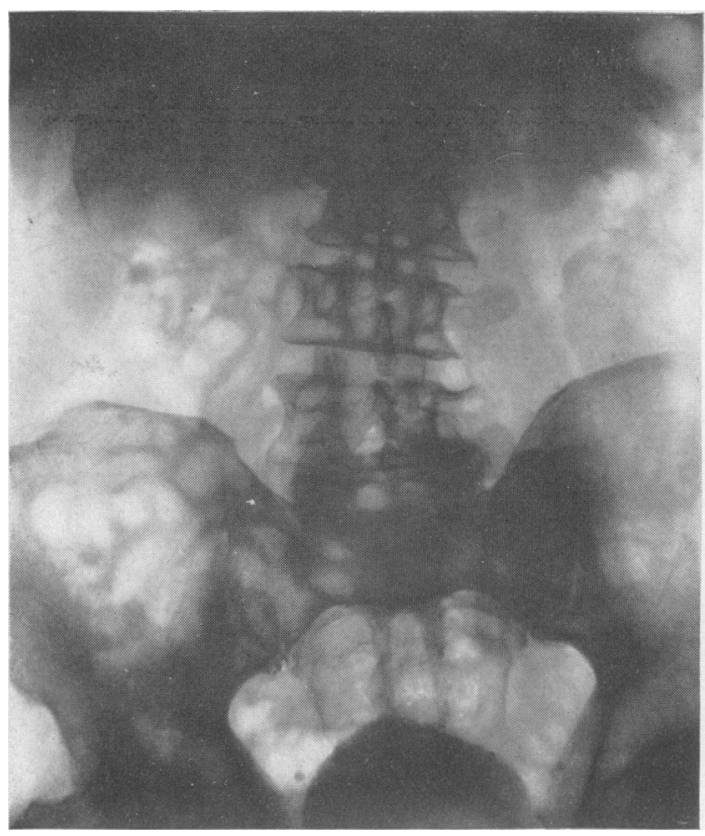

FIG. 5.- Showing a calcified pericyst in each of two hydatid cysts discovered during an X-ray examination of the urinary tract. Patient aged eight years.

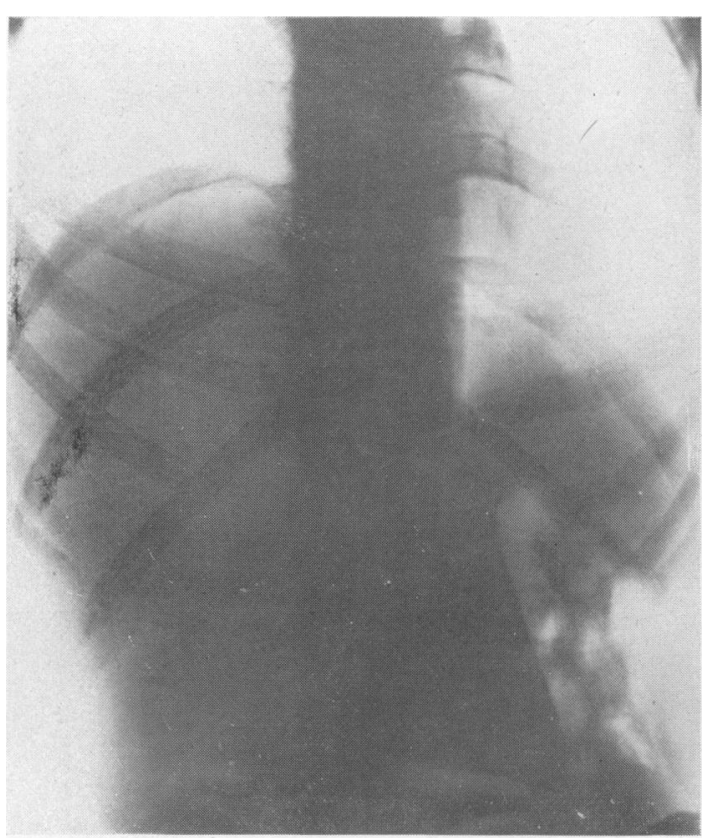

FIG. 7.-Case G. Showing elevation of the diaphragm resulting from a large cyst in the right lobe of the liver.

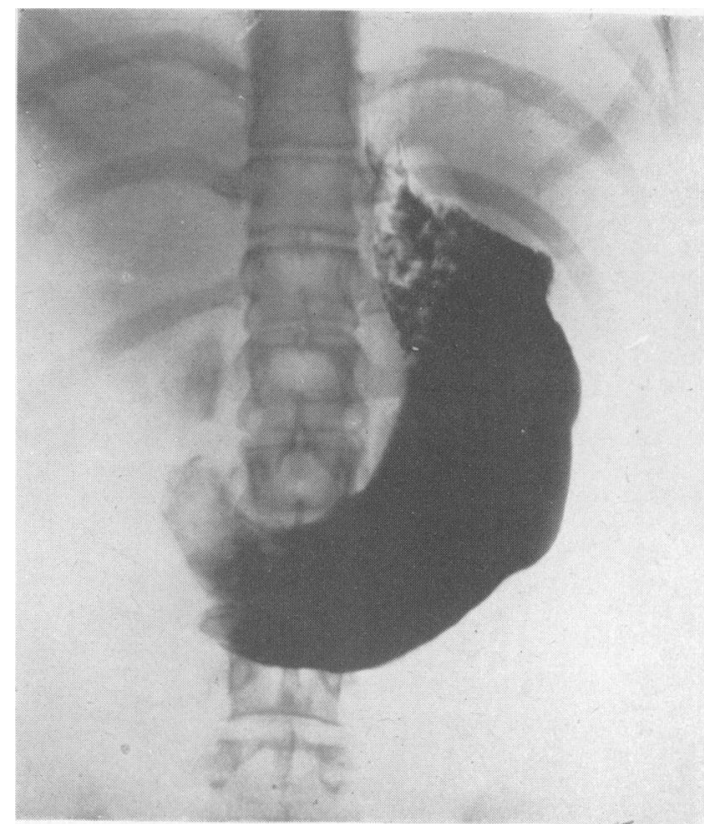

FIG. 6.-Case F. Showing a barium meal with gross distortion of the fundus of the stomach by a hydatid cyst under the left diaphragm. 'The outine of the cyst is clearly seen.

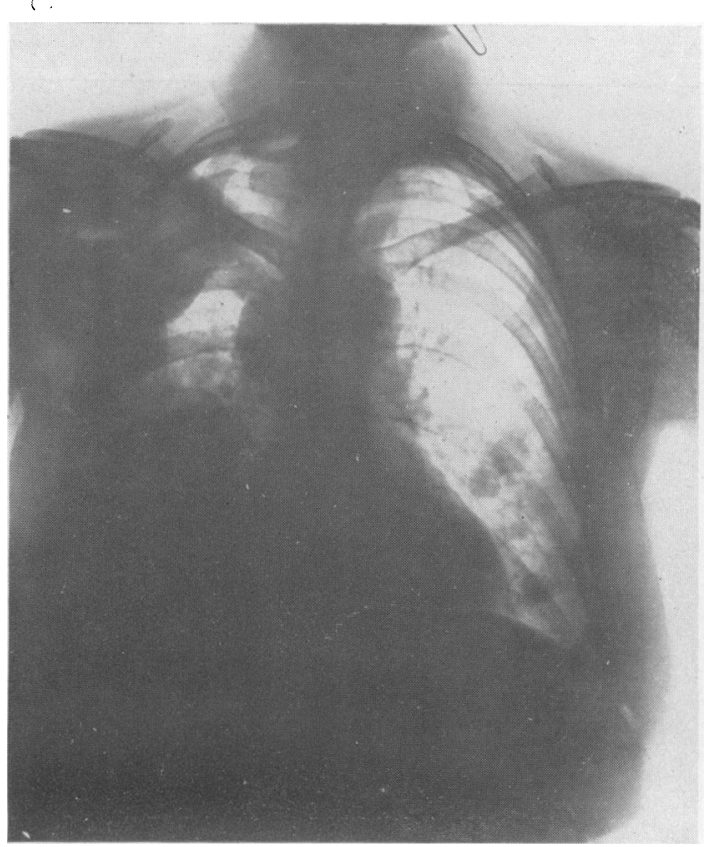

Fic. 8.-Case H. Showing in the left lung several cysts approximately $\frac{3}{4}$ in. in diameter. In the right lung there are multiple cysts of varying size. 


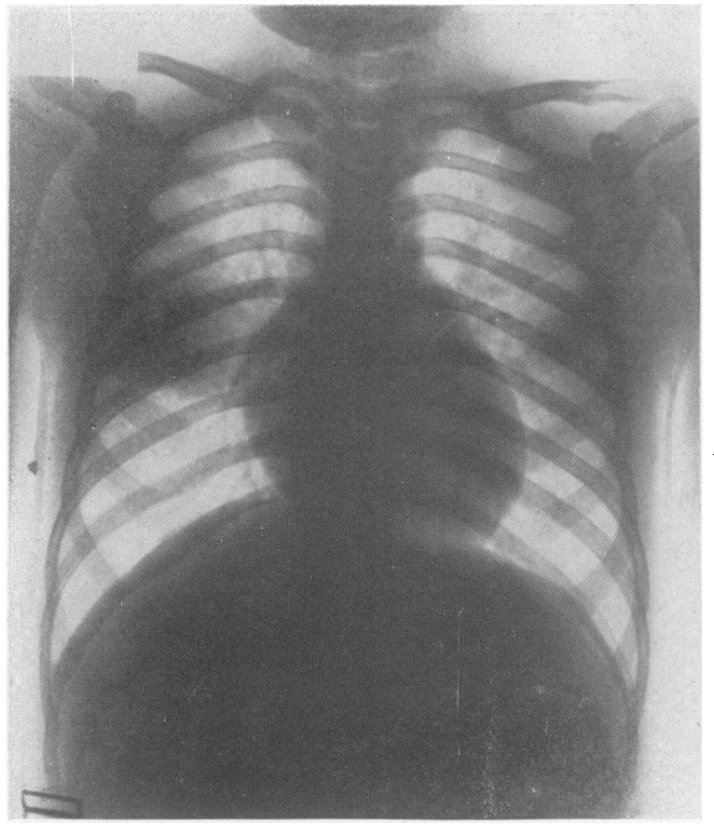

FIg. 9.-Case I. Showing a hydatid cyst in the right lung.

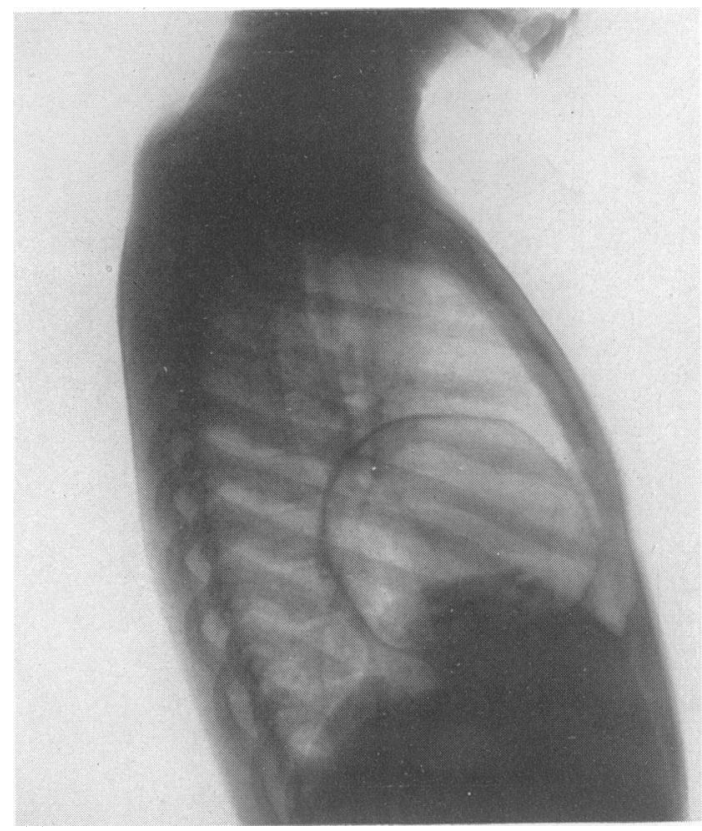

Fig. II.-Case K. Showing a large ryst with the hydatid membrans presenting the characteristic wavy mass ("Sign of the Camelote').

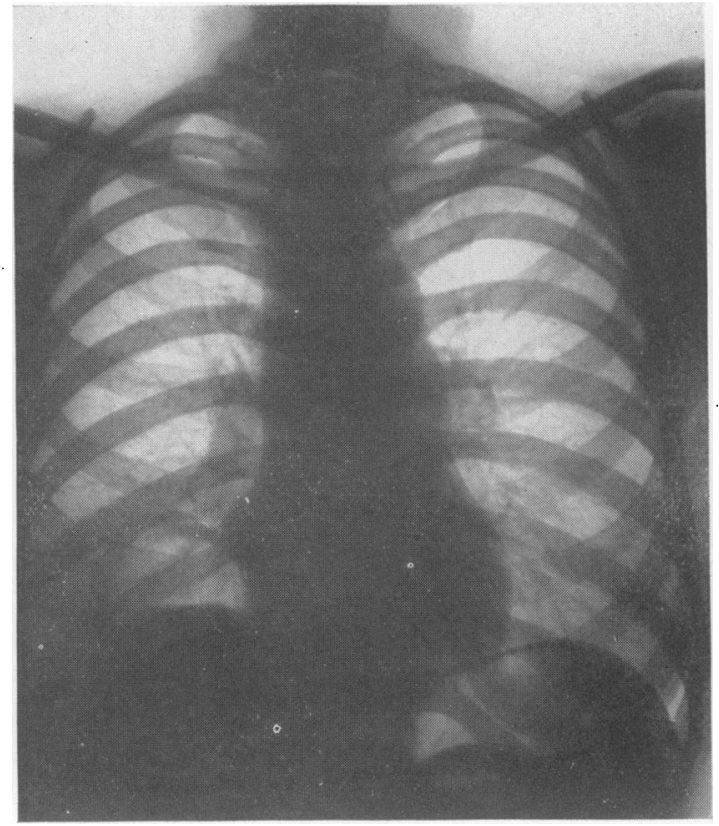

FIC. I o.-Case J. Showing a circular shadow of increased translucency in the lower part of the right lung with what is probably collapsed hydatid membrane in the lower part of the cyst.

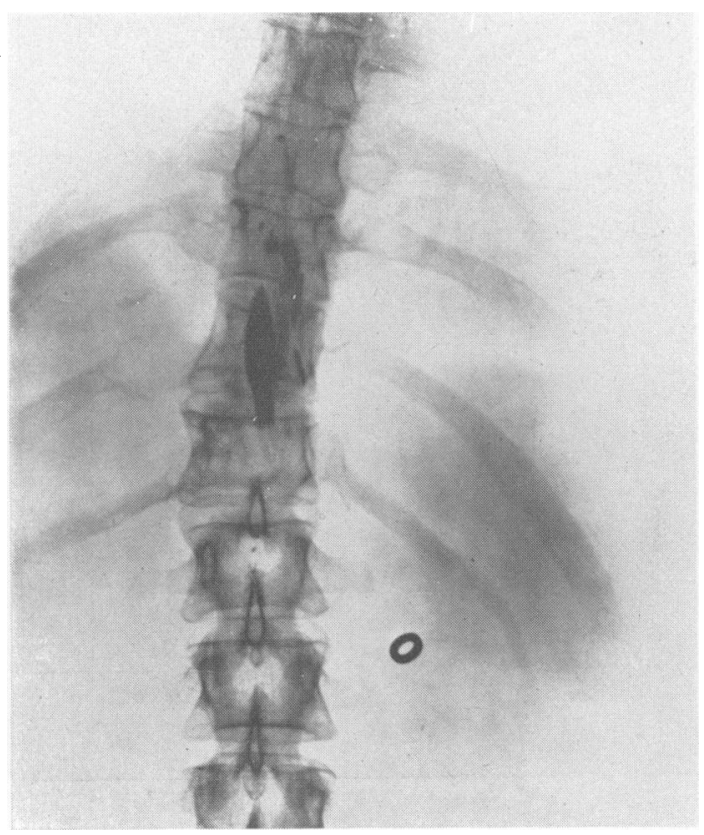

Fig. 12.-Case L. Myelogram showing blockage at level of T. 12. Medium injected into cisterna magna. Note erosion of ribs and vertebrae. 
FIc. 13.-Case M. Showing hydatid invasion of ribs.

Fif. I4.-Case X. Lipiodol myclogram showing deformity of lower end of thecal column by extradurial tumour on right side at lumbosacra! leve!.

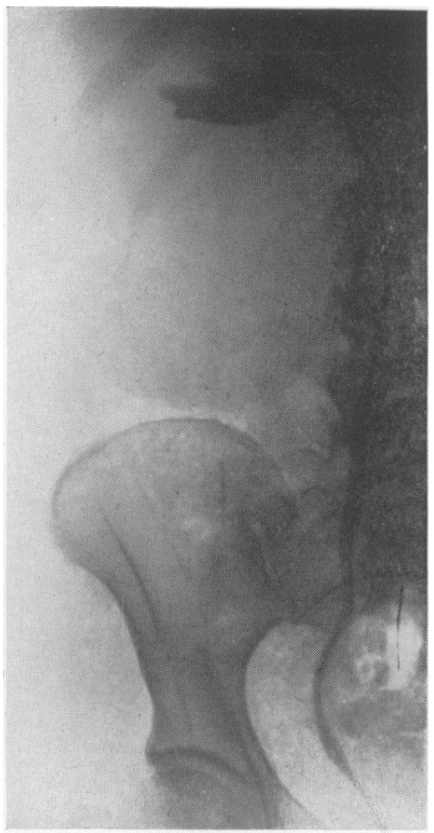

FIc. I5.-Case O. A retrograde pyelogram with appearances suggestive of a hypernephroma. The ureter is displaced. The pelvis of the kidney is obliterated and there is elongation and deformity of the upper and lower major calices.

FIg. 16.-Case P. A retrograde pyelogram showing a large tumour mass which caused rotation of the kidney, some hydronephrotic changes and displacement of the ureter. 
closing the pericyst and leaving a drain down to it, but here again the hazard of infection occurs.

In view of the great rapidity with which the huge cavity shrinks, the frequency with which bile leaks into it and, finally, the need for drainage in a considerable percentage of closed cases, the " no drain' method stands on trial at the present time. One final warning should be given regarding the handling of the pericyst. There must be no trauma with finger, spoon or other instrument to the wall of the cavity as large vessels and ducts may be eroded, and but a fragile membrane may separate the cavity from the duct lumen.

\section{HYDATIDS OF THE LUNGS}

Hydatid cysts in the lung may arise in several ways :-(a) The hexacanth embryo may pass the filter of the portal circulation and so reach the lungs. This probably accounts for solitary lung cysts (Fig. 2). (b) Leakage of a liver cyst or cyst elsewhere into the venous system may lead to multiple lung cysts, which will usually be of approximately the same size (see the left chest, Fig. 8). (c) Liver cysts may erode the diaphragm and secondarily involve the lungs.

Lungs presenting numerous cysts of varying ages and sizes are difficult to explain. Intermittent rupture of pulmonary cysts into the bronchial tree with subsequent implantation of scolices throughout the lungs is a possibility. Intrapulmonary vascular spread is also a possible explanation.

Case H.-Illustrating multiple lung cysts of various sizes.

A woman, aged 53 years, was admitted in July, 1945, giving a history of pain in the chest and of spitting of blood for 16 months in amounts varying from $\mathrm{I} \mathrm{oz}$. to $5 \mathrm{oz}$., at approximately monthly intervals. She gave a history of pneumonia two years previously and of pleurisy four months prior to admission. A diagnosis of cholecystitis had also been made recently elsewhere.

On examination there were marked physical signs in both lungs. The Casoni test was weakly positive (immediate). The delayed reaction was negative. The hydatid complement fixation test was strongly positive. Eosinophilia, 7 per cent. An X-ray of the chest disclosed multiple cysts in both lungs, four in the left lung of approximately equal size, and innumerable cysts in the right lung of varying size (Fig. 8).

Operation. On 10.7.45, 7 in. of the eighth, ninth and tenth ribs were resected on the right side and multiple cysts of the pleura were removed. These cysts were mostly less than $I$ in. in diameter, and lay in a thickened adherent pleural covering. (They were probably due to the intrapleural rup- ture of a lung cyst.) One large cyst was evacuated. 'There was a bronchial fistula into the pericyst. A cyst was palpated through the diaphragm and this was also evacuated. The wound was loosely packed with sulphanilamide and flavine gauze.

On 4.9.45 the cysts in the upper part of the right lung were dealt with; 3 in. of the third, fourth and fifth rib were removed posteriorly. Many pleural cysts were encountered and one lung cyst. The wound was packed as before.

On 24.9.45 the large cyst near the mediastinum and several smaller cysts were removed. The wound was packed as before. The patient was discharged on 19.10.45 with all wounds healed.

Comment. Palliation alone is possible in cases of this nature. The probable sequence of events had been the rupture of a lung or liver cyst into the pleural cavity with resulting obliteration, the seeded secondary hydatid cysts being enclosed in the thickened pleural membrane. At a later stage a larger lung cyst communicated with a bronchus. A possible explanation for the cysts in the left lung is given above.

Another interesting feature in this case was the finding of fibro-caseous tuberculosis in some lung tissue removed with the pleural cyst.

The ' life' of a lung cyst depends mainly on its avoidance of pressure on a bronchus, obstructive effect on pulmonary tissue, or secondary inflammatory change. Cysts in children usually grow to about 3 in. in diameter before complications occur and in adults they are correspondingly larger. When a cyst erodes a bronchus the hydatid membrane may remain intact, but sooner or later rupture is liable to occur. This is characterized by flooding of the bronchial tree with the typical watery fluid content of the cyst. Daughter cysts are relatively uncommon. The hydatid membrane may be expelled and spontaneous cure take place, but usually they separate from the pericyst and remain as a loose mass within the cavity. Secondary infection is only too probable, resulting in chronic lung abscess. Insidious leakage of the watery cyst content is of commoner occurrence than a sudden acute rupture, and this may lead to partial separation of the membranes from the pericyst and the ' single arc sign,' or the 'sign of the camelote' may be seen radiologically (Jenkins I946).

Rupture into the pleural cavity is uncommon. Injudicious use of an exploring needle may readily precipitate this disaster. Hydatid pneumothorax, haemothorax and pressure pneumothorax may occur, and at a late date secondary echinococcosis may develop in the pleura, lung or ribs (Case $\mathrm{H}$ ).

Pneumonitis and pleuritic pain are common results of pressure and infection. As the cyst approaches the visceral pleura pressure may induce pleural adhesions. 
The pericyst varies enormously in lung cysts and on its state largely depends whether a simple drainage operation or a lobectomy should be performed. In uninfected peripheral cysts, the pericyst is usually thin and pliable, and when the cyst is opened and the membrane removed, there is nothing to prevent the lung from re-expanding freely and occupying the space previously occupied by the cyst.

Case I.--Illustrating a solitary cyst of the lung, ' single arc sign.' probably present.

A boy aged $7 \frac{1}{2}$ had suffered pain in the right side of his chest for $2 \frac{1}{2}$ months before admission. Cough had been troublesome and he had been out of sorts and had run intermittent temperatures up to $103^{\circ} \mathrm{F}$. A radiograph (Fig. 9) showed a shadow suspicious of a hydatid cyst. It was thought that Cumbros sign or the ' single arc sign' was present. Both the hydatid complement fixation test and the Casoni tests were strongly positive. On physical examination the breath sounds were loud, with prolonged expiration in the right axilla at the level of the sixth rib.

Operation, 1.9.45. Local anaesthetic, I per cent. procaine; $2 \frac{1}{2}$ in. of the fourth and fifth ribs were removed. The pleura was adherent over a small area, and the pericyst was entered without involving the pleural cavity. The membranes were removed. There were no daughter cysts. The cavity was wiped out with formalin, there being no bronchial communication. The cavity was drained for a few days. The child was discharged healed and well 18 days after operation.

Comment. If the pleura had not been found adherent, and this can be ascertained without opening the parietal pleura, a two-stage operation would have been performed. The absence of a well-formed pericyst permitted the expanding lung tissue to obliterate rapidly the cavity left after the removal of the cyst. In cases such as these there can be no indication for lobectomy with its added risk. Even in the presence of multiple bronchial fistulae into the pericyst, rapid healing will occur if there is no rigid-walled pericyst to maintain the patency of the cavity.

Case $\mathcal{F}$.-Illustrating an infected cyst communicating with a bronchus.

A woman aged 49 was seen on 4.3 .47 giving a history that three weeks previously she had coughed up about 2 pt. of watery fluid followed by blood. Her doctor suspected a hydatid cyst. The radiograph (Fig. 10) showed a circular shadow of increased translucency in the lower part of the right lung partly hidden by the dome of the diaphragm. What is probably collapsed hydatid membrane is seen at the lower part of the cyst.
Both the hydatid complement fixation test and the Casoni test were strongly positive. Physical examination revealed dullness at the right base with diminished breath sounds. A coarse, short, rasping sound was heard during the inspiratory phase.

Operation, 17.3.47. Intratracheal anaesthesia ; 7 in. of the eighth rib were excised and $\frac{1}{2}$ in. removed from the posterior end of the seventh rib. The pleura was densely adherent and the lung tissue felt semi-solid. The cyst could not be defined owing to its collapsed state and the change in the surrounding lung tissue. On account of the patient's general condition lobectomy was decided against. The pericyst was cut into and collapsed membrane representing a cyst of 6-7 in. in diameter was removed. No daughter cysts were present. There was much muco-pus present and the openings of several large bronchi could be seen. The cavity was lightly packed with flavine sulphanilamide gauze and a drain inserted. She was discharged from hospital 27 days after operation with a large sinus having visible fistulous openings of bronchi at its inner end. These openings were cauterized with silver nitrate at intervals during the next month and the wound was completely healed and the patient symptom free by 6.6.47.

If there has been long-standing fistulous com气 munication between the hydatid cyst and bronchus associated with infection, there will be fixed sclerosed unyielding pericyst, and it may be greatly in the patient's interest to perform lobectomy if it can be safely carried out. Damage to the bronchial tree shown by a bronchogram may be an added indication for this procedure.

Case $K$ (Fig. I 1 ).-Illustrating a large infected cyst in a child in whom lobectomy was carried out.

A female, aged 6 years, was referred in October, r944. She was said to have had a left sided pneumonia four months previously. At intervals since then she had developed temperatures. There was no cough or sputum, and there was no history of coughing up any clear fluid. Radiological examination showed a large cyst with the hydatid 9 membrane showing the characteristic wavy mass (' sign of the camelote'). On November 3 rd, under local anaesthesia and intratracheal gas and $N$ oxygen, the chest was opened. The cyst wall (pericyst) was very thick and rigid. The pressures within the cyst showed, by tapping it with a fine $\mathrm{N}$ needle, that it communicated with a bronchus. Further examination revealed that the cyst lay 0 entirely within an expanded middle lobe. The middle lobe and the enclosed cyst were removed, $\stackrel{?}{\rightarrow}$ the bronchus being closed with interrupted cotton $T$ sutures. Convalescence was without incident and the patient was discharged healed on the 2oth day 
Comment. If drainage had been carried out in this case it would have been prolonged and it is probable that a residual cavity communicating with the bronchus would have persisted throughout life. Chronic bronchiectasis would have been likely

\section{The Surgical Treatment of Lung Cysts}

As with a lung abscess, so with hydatid, both are ' infected' in their own way. No needle should ever be put through a chest wall for diagnostic aspiration of a suspected lung cyst. The resulting disaster may be as great as with lung abscess.

In simple uncomplicated cysts careful localization should be carried out, and segments of two ribs resected over the point at which the cyst is nearest to the chest wall. When the extra-pleural plane is freely exposed one can see whether or not the lung is adherent. If the parietal pleura is thickened and there is no sign of movement of the underlying lung, entry can be made directly into the lung at this point. The area of adhesion may be limited to an inch or less.

If adhesions are not present it adds but ten days (to the many years the hydatid has been present) to induce their formation by an extrapleural iodine gauze pack. A high percentage of these cases has to be drained on account of bronchial fistula or sepsis. One does not know before operation what the interior of the pericyst will present as the tense membranes may be occluding an opening into one or more bronchi ; openings that become only too apparent once the membranes are removed. The risk of the cavity in the lung, with its associated bronchial fistula, producing pressure pneumothorax due to faulty suturing or to stitches cutting out, is too high to permit of pleural suture and immediate evacuation.

If forced to do a one-stage operation in the absence of pleural adhesions, a water seal drainage of the pleural cavity should be carried out. The use of formalin in lung cysts is to be strongly condemned except for swabbing the pericyst in the absence of bronchial fistula. Some textbooks advocate injecting formalin into the cyst before opening it, as is done in the case of liver cysts, but this procedure carries many dangers as the formalin may enter the bronchial tree if a fistula is present.

Small cysts lying deeply in the lungs are best left alone. The size and progress of the cyst should be watched by radiograms at yearly intervals. Where there are multiple cysts the same principles of treatment apply as in the single cyst, but it is often possible to drain two or more cysts through one approach. The prognosis in lung cysts is good, both as regards absence of recurrence and subsequent lung function, providing ' no spill technique' and a careful choice of procedure is adopted. The case becomes almost hopeless once intrapleural dissemination with involvement of ribs and intercostal structures occurs.

\section{HYDATIDS INVOLVING THE VERTEBRAL GOLUMN}

I have encountered three of these cases and they conform to type to an extraordinary degree. In two cases there has been a life-long history of pulmonary hydatid, both patients being past middle age. Repeated operations have been performed elsewhere for pulmonary cysts, extrapleural tissues involved, and the body of one or more vertebrae invaded. The course of the disease has been insidious and progressive. One can assume that at the original operation, had spill been avoided, the story might have been a very different one.

The extraordinary changes in the response of the hydatid to its environment are strikingly exemplified by these cases. In the lungs there is formation of large cysts of the usual type ; in the area adjacent to the spine, intervertebral foramina and spinal canal are cysts mostly $\frac{1}{4}$ to $\frac{1}{2}$ in. in diameter, free and without pericyst, while in the cancellous bone of the vertebrae are cysts of a minute sago-grain structure causing diffuse destruction. Another feature is the apparent ability of the cysts to derive essential nourishment from the body fluid when they are lying free in tissue spaces and not surrounded by a pericyst. In each of these cases cysts had worked through the intervertebral foramina and caused extradural pressure and paraplegic symptoms. The tendency for the cysts in spreading to take the line of least resistance, via the intervertebral foramen is very striking. In each case at laminectomy an extradural cyst was found. When the intervertebral foramen was investigated and further bone removed, cysts were found in an extrapleural position.

Case L.-Illustrating hydatid of lung and vertebrae.

A female, aged 45 years, was seen in consultation with Mr. Murray Falconer, to whom I am indebted for permission to use this record. The patient was admitted to the Neurosurgical Department with symptoms of cord pressure.

In 1920 , at the age of 21 , she suffered from pleurisy. At the age of 25 she was admitted to a sanatorium for chest complaints and remained there for four years. The condition which had been suspected as being tuberculosis was then found to be hydatid. She had an operation for lung hydatids in 1928 . In 1929 she coughed up a cyst and this was followed by multiple haemor- 
rhages and further coughing up of cysts. In 1936 she had a further lung operation followed by coughing up of more cysts, pus and blood. In I 943 and 1944 she had abdominal operations for hydatid cysts.

Neurological examination confirmed pressure on the cord at the level of the i2th thoracic vertebra (Fig. 12). X-ray examination showed destruction of the inner end of the IIth and I2th ribs, and the transverse processes and pedicles of the I Ith and I2th thoracic vertebrae. Changes are seen in the IIth and r2th thoracic vertebral bodies on the right side

At operation a large cyst was found in the lower part of the right lung. This was adherent to the side of the vertebral column and had eroded it. Numerous daughter cysts were present and the disease extended through the intervertebral foramina to involve the extradural space. A right, hemilaminectomy and costotransversectomy revealed a mass of daughter cysts up to $I \mathrm{~cm}$. in diameter along the right lateral border of the theca. Removal of the 12 th rib and right transverse process freed a large collection of cysts below the diaphragm with further cysts in the liver. The diaphragm appeared to be intact. On discharge $2 \frac{1}{2}$ months later the cord pressure was relieved and the wound was healed.

She was readmitted in December, I945, complaining of low back pain. There was no evidence of spinal cord pressure. Multiple cysts were removed from the base of the right lung.

The next admission was in September, 1947. She was suffering severe pain, and had difficulty with micturition. There had been further operations for cysts and an Albee operation performed elsewhere. Operation was undertaken on 19.9.47 by $\mathrm{Mr}$ James of the Neurosurgery Department and myself. The dura was found to be absent at the level of the I th thoracic vertebra on the right side and several cysts extended intrathecally. There was marked pressure on the cord. The body of the I2th thoracic vertebra was a mass of sago grain-like material; it was vascular, soft and spongy and contained millions of pin-head cysts. The whole of this was curetted away leaving part of the shell of the vertebral body. The adjacent discs were removed. The erector spinae muscle was split and the inner part used to repair the dural defect and to fall into the bone cavity. On 7.11.47 a massive bone graft was applied bridging the gap left by the loss of the body of the 12th thoracic vertebra. Healing was satisfactory. Up to the present time there has been no further evidence of pressure on the cord.

Case $M$. - Illustrating hydatid disease of lung and vertebrae.
A male, aged $5^{2}$ years, was first seen in November 193 I complaining of pain in the dorsal region with evidence of spinal cord pressure, both being present for three months prior to admission. Forty years previously, at the age of 12 , he had had a hydatid of the left lung removed. At the age of I9 he coughed up hydatid cysts. Three years later he coughed up more cysts. Some years later a cyst burst through the front of his left chest. Twelve years ago he had cysts removed from the back of his neck. Five years ago he was operated on for further cysts in the lungs.

On examination he showed signs of pressure on the cord at the fifth dorsal segment. The Casoni and hydatid complement fixation tests were both strongly positive. An X-ray showed much pleural thickening with cysts lying in the posterior part of the left lower lobe, their medial borders in close relationship to the vertebral bodies. No bony lesion was detected.

At operation a laminectomy was performed and a cyst was found in the extradural space causing pressure on the cord. It had an hour-glass shape, extending through an intervertebral foramen, part of the cyst being within the spinal canal and part within the thorax. Removal of transverse processes revealed a cavity containing further small cysts. This space was extrapleural and the bod $g$ of the sixth dorsal vertebra and its transverse pro? cess were eroded. The spinal theca was not opened during the operation. The patient mader a satisfactory recovery and lost all symptoms of cord pressure.

He next reported in February, 1944, again with pain in the dorsal spine and gross pulmonary disturbance. He was very toxic and was coughing up copious offensive sputum. X-rays showed further cysts in the left lung. Under local anaesthesia and pentothal an attempt was made to provide drainage. The ribs were diffusely involved with hydatids, as were the soft tissues of the chest wall. The vertebral bodies were eroded and there were three cysts in the lung. All these structures were adherent and the spread of the disease was apparently by a continuous process of infiltration by the disease (Fig. I3, showing erosion and destruction of ribs).

Case N.-Illustrating hydatid disease of the $N$ sacro-iliac region.

A female, aged 20, was admitted under Mr. M. Falconer on 7.10 .43 with a provisional diagnosis of sciatica due to a prolapsed intervertebral disc. She had suffered low back pain and sciatica for I 8 months. This had been very severe at times. She had recently experienced difficulty in emptying her bladder. On examination there were muscular wasting and sensory changes in the right 
leg, and neurological investigation suggested an extradural tumour at the fifth lumbar - first sacral level. A prolapsed nucleus pulposus was considered likely, though an extradural tumour was suggested by the large size of the filling defect (Fig. 14).

At operation Mr. Falconer found an extradural hydatid cyst arising from the body of the second sacral vertebra. It was roughly $5 \mathrm{~cm}$. in diameter, and had eroded completely through the sacrum exposing the pelvic fascia on its deep surface. There was no visible pericyst. After operation the hydatid complement fixation test was strongly positive.

She was readmitted in December, 1945, when Mr. Falconer asked me to see her in consultation. She then had a firm, tender swelling in the right sacro-iliac region. She was running a temperature up to $100.5^{\circ} \mathrm{F}$. Her hydatid complement fixation. was strongly positive and the Casoni test was indeterminate. X-rays of the bony pelvis and lumbar spine showed no appreciable bony abnormality. There were no fresh neurological signs or symptoms. At operation we found the sacrum and adjacent ilium riddled with hydatid cysts varying in size from a pin head to $1 \mathrm{~cm}$. diameter.

Comment. This third case of vertebral involvement appears to be a primary bone infection in that no lesion has been found elsewhere. The prognosis is very bad. The widespread infiltration of the sacrum and ilium makes complete removal impossible: With infiltration of cancellous bone radiological changes are in its early stages either absent or of such slight degree that the condition is likely to be missed.

\section{PRIMARY GYSTS IN OTHER PARTS OF THE BODY}

If the hexacanth embryo passes through the filter of the liver and the lung it is easily understandable that a primary cyst may occur in any part of the body. 'The kidney is involved in about 2 per cent. of crses

In the kidney the cyst may grow to large proportions, but rupture or leakage into the urinary tract is likely to occur sooner or later. Daughter cysts may pass down the ureter causing ureteric colic. Infection is common, leading to marked thickening of the pericyst, which may be fused with the expanded kidney capsule and surrounding structures.

Case $O$ (Fig. 15).-Hydatid simulating a renal neoplasm.

A female, aged 6r years, complained of pain in the right loin, and showed a large tumour mass in the left flank.

Investigation elsewhere had led to a diagnosis of hypernephroma. Examination revealed a very sick, hypertensive woman. A large rounded mass filled the left upper abdomen. The tumour presented in front like an enlarged spleen but no notch was felt. It did not fill the loin. An intravenous pyelogram showed a normal right kidney but only part of the pelvis on the left side, no calices being seen. Cystoscopy confirmed very poor function on the left side and a catheter could not be passed beyond $15 \mathrm{~cm}$. Bladder urine contained pus, though the urine from the right kidney was clear. Retrograde pyelograms (Fig. I5) gave an appearance not unlike that of a hypernephroma. The large rounded mass of the tumour was seen to cause displacement of the ureter and obliteration of the pelvis with elongation and deformity of the upper and lower major calices. At operation by a left loin incision a large, thick walled cyst was removed. The kidney was incorporated in its wall and the spleen was so densely adherent that both these structures were removed with it. Convalescence was satisfactory. The cyst was found to be full of pus, daughter cysts and hydatid debris. The kidney was an infected, fibrosed, functionless structure stretched over and forming part of the cyst wall.

Comment. Two procedures were possible in this case. The easier and probably safer was to open and drain the cyst. The patient would have had a very prolonged convalescence owing to the thickness, rigidity and infection of the pericyst. Radical removal was carried out in this case owing partly to the fact that at the commencement I thought I was dealing with a renal tumour, and later when the true position was disclosed it was deemed possible to complete its removal. Simple, non-communicating, uninfected cysts may be treated according to principles followed in the treatment of cysts elsewhere. In certain cases a partial nephrectomy may be possible.

\section{Case $P$ (Fig. 16 ).}

A female, aged 65 years, was admitted to the medical ward with epistaxis. She was markedly hypertensive, systolic blood pressure 262 , diastolic 70. In the course of examination a tumour was found in the right flank. The tumour was rounded, tense and cystic. On its lower anterior surface it was irregular and firm. Intravenous pyelograms showed no function in the right kidney. A retrograde pyelogram (Fig. 16) revealed a large tumour mass causing rotation of the kidney, slight hydronephrotic changes and displacement of the ureter. Urea concentration tests showed 2.54 per cent. in the fourth specimen. The Casoni test was negative. At operation a large hydatid cyst was found tightly packed with daughter cysts. This was emptied, formalized and drained. Convalescence was uneventful. The firm, irregular 
area was a 2 in., smaller degenerate cyst attached to the large cyst.

\section{Summary}

Only certain aspects of the wide field of hydatid infection have been touched upon in this paper. In many cases the surgical problems are comparatively simple, but not in all, and I have attempted to present the disease as I have seen it. It will be apparent that there can never be a 'best single method' for there is a greater demand for adaptability and versatility in the treatment of this disease than for any other surgical condition. Finally the thought must ever be in the operator's mind that 0 'spill' may mean life-long suffering for the $\bar{c}$ patient.

\section{BIBLIOGRAPHY}

BARNETT, L. E. (1927), M. F. Aust., 2, 878. HUTCHINSON, JONATHAN (1890), Arch. Surg., I, 318. JENKINS, JAMES A. (1931), Brit. $\mathcal{F}$. Surg., 18, 585.

JENKINS, JAMES A. (1946), Aust. and N.Z. F. Surg., 15, 296 MEAD, A., and BARNETT, L. (1941), Aust. and N.Z. F. Surg. I0, 317 .

SYME, G. A. (1909), Brit. Med. f., 2, 956.

\section{BOOKS RECEIVED}

The Editorial Board acknowledge with thanks the receipt of the following volumes. A selection from these will be made for review.

'An Atlas of Bone-Marrow Pathology.' By M. C. G. Israels, M.Sc., M.D., M.R.C.P. Pp. x + 79. With 12 plates in colour. London: William Heinemann. 1948. 3os.

'Abdominal Operations.' By Rodney Maingot, F.R.C.S. 2nd Edition. Pp. xxiii + r274. With 468 illustrations. London: H. K. Lewis. 1948. $84 s$.

'Neurological Anatomy in Relation to Clinical Medicine.' By A. Brodal, Oslo. Pp. xv +496. With 94 illustrations. London; Geoffrey Cumberlege, Oxford University Press. I $948.42 s$.

- Malignant Disease and its Treatment by Radium.' By Sir Stanford Cade, K.B.E.; C.B., F.R.C.S., M.R.C.P. 2nd Edition. Pp. xi +430 . With 205 illustrations, many in colour. Bristol : John Wright and Sons. 1949. 52s. 6d.

' Textbook of Medical Treatment.' By D. M. Dunlop, M.D., F.R.C.P., L. S. P. Davidson, M.D., F.R.C.P., and J. W. McNee, D.S.O., M.D., F.R.C.P. 5th Edition. Pp. xvi +999 . With 40 illustrations. Edinburgh : E: and S. Livingstone. 1949. 35 s.

'Aids to Biochemistry.' By E. A. Cooper, D.Sc., F.R.I.C., A.R.C.S., and S. D. Nicholas, B.A., A.R.I.C. 4th Edition. Pp. viii +244 . With II illustrations. London: Baillière, Tindall and Cox. 1948. 5s.

'Aids to Physical Chemistry.' By R. G. Austin, B.Sc.(Lond.), F.R.I.C. 2nd Edition. Pp. xii + 443. With 6r illustrations. London: Baillière, Tindall and Cox. 1948. 7s. 6d.

'Handbook of Surgery.' By Eric C. Mekie, M.B., Ch.B., F.R.C.S.(Ed.), F.I.C.S., and Ian Mackenzie, M.B.E., M.B., Ch.M., F.R.C.S. (Ed.). 2nd Edition. Pp. xvi +764 . With 29 illustrations. Edinburgh : E. and S. Livingstone. 1949. 20 s.
'Your Hospital, Heritage and Future.' By으 A. R. J. Wise, F.H.A. Pp. $x v+$ 239. Illustrated.London : William Heinemann. r949. I5s. 'Aids to Psychology.' By John H. Ewen, F.R.C.P.E., D.P.M. 3rd Edition. Pp. vii $+192 .-$ London: Baillière, Tindall and Cox. 1948.

'Psychological Medicine.' By Desmond Currah, M.B., F.R.C.P., D.P.M., and the late Eric Gues mann, M.D., M.R.C.P. 3rd Edition. Pp. viii 252. With 20 illustrations. Edinburgh: E. and S. Livingstone. I949. I2s. $6 \mathrm{~d}$.

'The Harveian Oration: The Structure of $\frac{\varrho}{\varrho}$ Medicine and its Place Among the Sciences.' By F. M. R. Walshe, M.D., D.Sc., F.R.C.P., F.R.S.을 Pp. 26. Edinburgh : E. and S. Livingstone. I 948. Is. 6 d.

'The Scotsman's Food.' By A. H. Kitchin, M.B., and R. Passmore, M.A., D.M., F.R.S.E. Pp. 88. Edinburgh : E. and S. Livingstone. 1949. 3s. 6d.

'Rational Medicine.' By J. W. Todd, M.D., M.R.C.P. Pp. viii + 378. Bristol : John Wright and Sons. 1949. 25s.

'Practical Orthoptics in the Treatment of Squint.'? By T. Keith Lyle, M.A., M.D., M.Chir., M.R.C.P., F.R.C.S., and Sylvia Jackson, S.R.M., D.B.O. 3 rd Edition. Pp. xii +27 r. With $\mathrm{r}_{5} \mathrm{r}$ illustrations, $N$ including three coloured plates. London: $\mathrm{H}$. K. Lewis. 1949. 35 s.

'Brompton Hospital Reports. Vol. XVI.' Published by the Research Department of the Hospital. Pp. 248. Profusely illustrated. Ios.

'A Method of Anatomy.' By J. C. Boileau Grant, M.C., M.B., Ch.B., F.R.C.S.(Ed.). 4th ${ }^{+}$ Edition. Pp. xxiv +852 . With 800 figures. $\frac{T}{0}$ London: Baillière, Tindall and Cox. 1948. 38s. 6d. 